
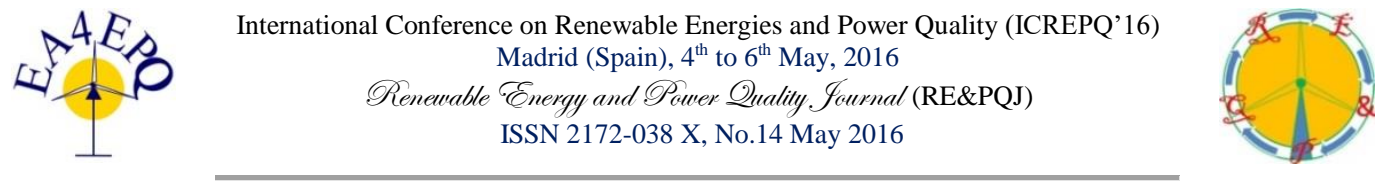

\title{
Influence of HVDC P2P Links on Static Voltage Stability in Transmission Grids with High Shares of Renewable Energy
}

\author{
F. Bennewitz, N. Hoesch and J. Hanson \\ Department of Electrical Power Supply with Integration of Renewable Energies (E5) \\ Technische Universität Darmstadt \\ Landgraf-Georg-Str. 4, 64283 Darmstadt (Germany) \\ Phone number: 0049 -6151 - 16-24666, e-mail: fb@e5.tu-darmstadt.de
}

\begin{abstract}
The Energiewende with the massive installation of renewable energy sources (RES) in the distribution grid leads to major changes in the transmission system. RES are often installed at sites with a high yield of primary energy, which results in higher average transmission distances. Thus, reactive power demand increases, which affects static voltage stability. To address these challenges, technologies like High Voltage Direct Current (HVDC) Point-to-Point (P2P) links will be used in the transmission grid. Within this paper an iterative load-flowalgorithm is proposed to evaluate voltage stability margins, i.e. the distance from the actual operating point to the stability limit regarding active power transmission. Due to the possibility of modern Voltage Source Converters (VSC) to control active and reactive power independently, voltage stability limit is investigated for different loadings of the HVDC P2P links. A 58bus-transmission grid representing the German transmission system is used, where regional distributed renewable feed-in as well as three HVDC P2P links are applied. The dispatch of conventional power plants is determined through a merit-order approach. Results show that HVDC-links can have a positive effect on voltage stability depending on their power transmission. The choice of the operating point can therefore be crucial for voltage stability.
\end{abstract}

\section{Key words}

HVDC, load flow, power balance, RES, voltage stability

\section{Introduction}

Due to the German Energiewende major changes affect the power system with reference to the generation as well as the power transmission of the system. Because of the increase in share of RES, conventional power plants are replaced. These conventional power plants are placed near loadcenters, i.e. regions with high consumer loads. RES are installed at sites with a high yield of primary energy and thus not near the load centers. As a result, the average transmission distances rise causing higher reactive power losses in the system. The replacement of conventional power plants causes a loss of flexibility in terms of reactive power supply, due to missing reactive power and voltage control of conventional plants.

To tackle these problems, transmission system operators (TSO) plan to install HVDC P2P links in Germany. For this purpose modern VSC stations should be used, allowing the independent control of active and reactive power. The reactive power balance of the power system is severly changed by the rearrangement of power supply and transmission structure. Therefore, static voltage stability has to be evaluated to guarantee a sufficient stability margin for the operating points of the system [1].

\section{Investigated Power System}

The following chapters present the power system model, i.e. the transmission system (subchapter A) and generation and loads (subchapter B). To investigate unexperienced situations with high feed-in of RES, situations are chosen which may cover years beginning from 2030. The power system model has been developed within the OVANET project [2].

\section{A. Transmission System}

The aggregated model of the German transmission system used in this study is depicted in Figure 1. The aggregation is based on the model of regions as described in [3].

The model consists of 58 nodes with a nominal voltage of $380 \mathrm{kV}$, where the $220-\mathrm{kV}$-voltage-level has been converted to the $380-\mathrm{kV}$-level. To cover the situation in the power system with multiple TSOs and resulting crossborder flows, 45 of the nodes are considered to be domestic nodes, while the other 13 emulate the power system abroad. All of these nodes are connected by two parallel AC overhead lines, with typical 562-AL1/49ST1A overhead transmission lines [4].

Furthermore, three HVDC-transmission corridors are considered to strengthen the AC-grid between its northern and southern parts due to the RES-surplus within these areas. The converters have a rated power of $8 \mathrm{GW}$.

The mentioned simplifications of the transmission grid have been done to obtain a model which has faster calculation times than models with a more detailed grid structure. 


\section{B. Generation and Loads}

Prognoses for the German power system have been prepared to estimate possible power supply and transmission situations of the future. Afterwards, these prognoses have been scaled to the 58-node-model of the power system.

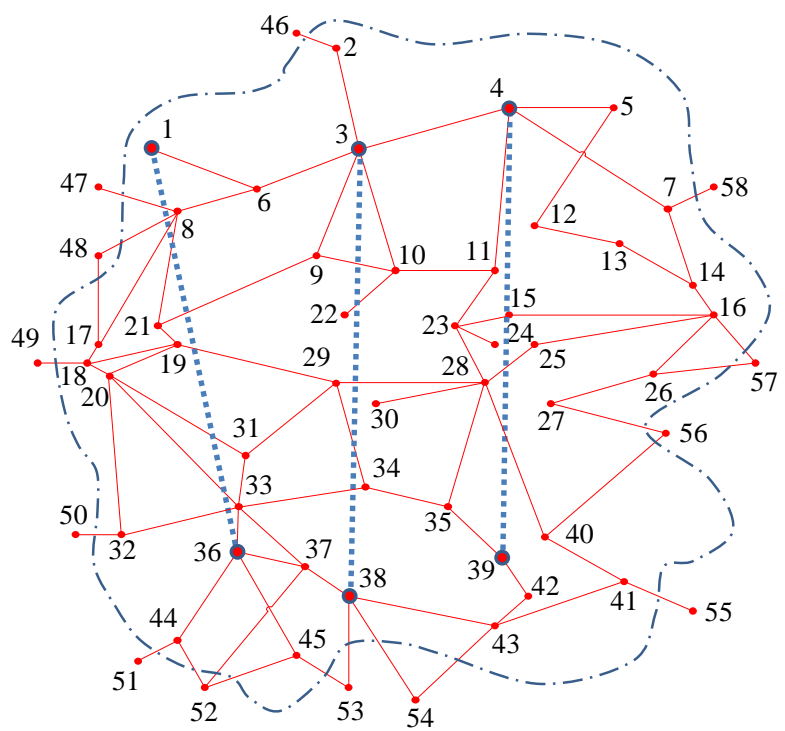

- AC-node $\quad$ AC-node with VSC-converter station

- AC-line ..... DC-line B Border

Figure 1: Aggregated Model of the Transmission System

Conventional power plants will be shut off in the upcoming years due to the installation of RES. Based on publications concerning changes within the generation system [5], it is possible to develop a scenario regarding conventional power plants in future decades, i.e. around 2030. Actual existing plants have been taken into account as well as planned installations and abandonments of power plants. The installations of RES are prognosed based on [3], which defines development paths for the different types of RES subdivided into ten different regions in Germany. With the development path, installations of RES can be assigned to the nodes of the transmission system. The same procedure has been chosen for the consumer loads. They are derived under the assumption, that there will be no major changes concerning consumer loads in the next years. To keep the computational order small, RES installations and consumer loads are directly allocated to the EHV-busbars of the transmission grid, i.e. the influence of the distribution grid is neglected. Total rated power of RES, conventional power plants and consumer loads are shown in Table 1.

Table 1: Total installed rated power

\begin{tabular}{|l|l|}
\hline Renewable Energy Sources & $P_{\mathrm{RES}}=168,69 \mathrm{GW}$ \\
\hline Conventional Power Plants & $P_{\mathrm{Conv}}=62,59 \mathrm{GW}$ \\
\hline Consumer Loads & $P_{\text {Load }}=85,00 \mathrm{GW}$ \\
\hline
\end{tabular}

\section{Evaluating Voltage Stability Limit}

The following chapters present the basic knowledge concerning voltage stability (subchapter A) and the iterative load-flow approach for determining the stability limit (subchapter B). Furthermore, information is given concerning the supply of active and reactive power (subchapter 0).

\section{A. Voltage Stability}

Voltage stability is defined as the ability of a power system, to keep the voltage levels at all busbars within the allowed tolerance bands during and after a disturbance according to [6]. This fundamental definition can be extended, if more detailed physical phenomenon taken into account. The load-demand of a consumer, supplied over a line from a stiff power system, is increased step wise. The increase of the load demand is equal to the decrease of the consumer impedance, while the transmitted power increases, which leads to a decrease of consumer voltage. At the point, where the consumer impedance is equal to the line impedance, power adjustment is reached and, thus, maximum power is transmitted over the line. A further increase of the consumer load cannot be satisfied and through the occurring power imbalance a breakdown ("voltage collapse") will occur. This point is called critical point, while the transmitted power and the consumer voltage is marked as $P_{\text {crit }}$ and $U_{\text {crit }}$ respectively, the corresponding behavior is shown in Figure 2 [7].

The voltage collapse can be further explained in terms of reactive power balance of the system. If the transmitted power increases, reactive power demand increase. Due to load-flow equations reactive power balance is tightly related to voltage level, i.e. an increased demand of reactive power leads to decreasing busbar voltages. According to [1] voltage collapse can therefore be understood as a local reactive power imbalance, which cannot be compensated by the system. Hence, in terms of voltage stability a careful observance of reactive power balance is needed.

\section{B. Iterative Load-Flow Approach}

To guarantee a sufficient margin between the actual operating point of the power system and the point where voltage collapse occurs, evaluation of the critical point of operation is needed.

An approach is chosen which samples the stability limit of the system in an iterative procedure. Based on the determined prognoses of the consumer loads, feed-ins of RES and cross-border flows, the power supply of the conventional power plants is estimated with a merit-order approach (subchapter 0 ). With this input data the operating point of the system is determined and the resulting load flow is calculated with the software MatPower [8]. By linearly increasing the consumer loads at the domestic nodes, which is compensated by the conventional power plants, the stress of the system, i.e. reactive power demand, is increased. System stress is at its maximum at the critical point, where voltage collapse occurs. At this point, the reactive power balance of the system cannot be kept, which leads to a blackout of the system. The consumer load at the critical point is further defined as voltage stability limit (VSL). This procedure is shown for one busbar in Figure 2. The shown curve is known as PVcharacteristic. If system stress, i.e. reactive power demand, 
is increased, busbar voltage decreases until the point, where the reactive power balance cannot be kept.

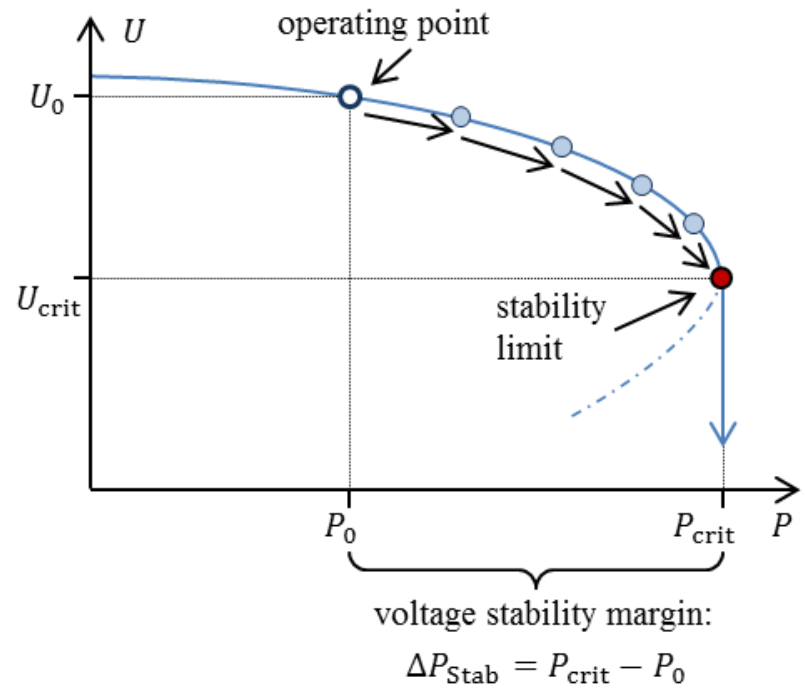

Figure 2: Sampled determination of voltage stability limit

The loading of the HVDC-links is crucial for voltage stability limit due to its capability to provide reactive power to the system (subchapter 0 ). To determine its influence on voltage stability, it is investigated by a stepwise increase in power transmission from $0 \%$ to $100 \%$ of rated power of the HVDC-links and a continued determination of voltage stability limit. The approach is shown in Figure 3.

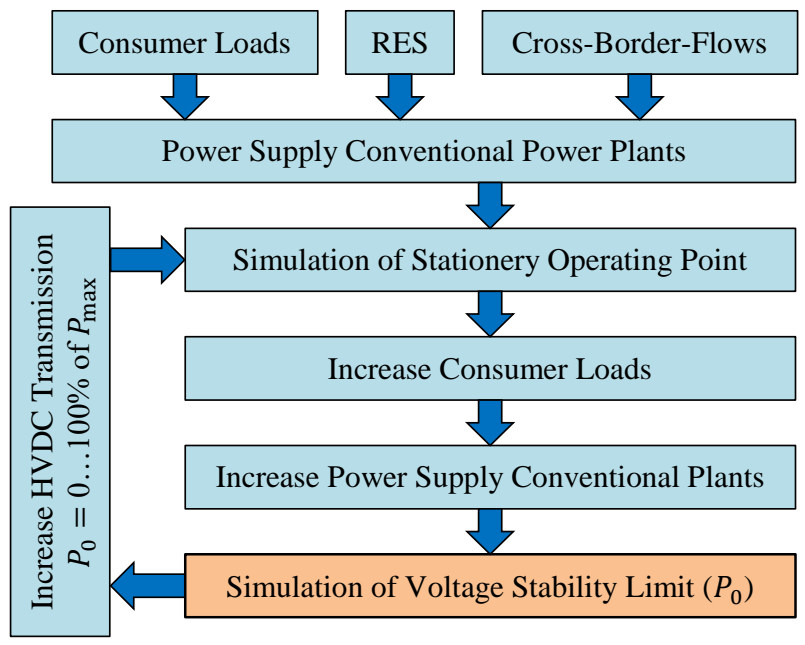

Figure 3: Determination of voltage stability limit for different HVDC transmission

\section{Active and Reactive Power Supply}

The conventional power plants are used to cover the difference between RES feed-in and consumer loads at the operating point. They also compensate the increase of consumer loads in the iterative approach. Due to the impossibility to consider the real market action, a simple merit order approach is used. The merit order determines which conventional power plants cover the load. The algorithm is based on the individual electricity production costs, which allows a grading of the different primary energies. Prices and costs have been taken from [9] and [10].
Reactive power can be supplied by several technologies in general. In previous days this supply was mainly adopted by the conventional power plants, which could adjust the individual supply of reactive power based on the needs of the power system with its exciting current throughout an over- or under-excited mode. This ancillary service has to be discussed due to the ongoing replacement of conventional power plants by RES. As a substitution RES might be considered itself, but also technologies like HVDC or FACTS are able to supply reactive power. In this study RES as well as HVDC converters are considered together with reactive power supply by conventional power plants.

The grid-connection of RES is regulated through different technical guidelines, for example [11] for the medium voltage level. If this regulation is taken as a reference for all RES installation, i.e. also for low-, high- and extrahigh-voltage-level, new RES must provide a power factor between $0,95_{\text {underexcited }} \leq \cos \varphi \leq 0,95_{\text {overexcited. The }}$ amount of RES, which have a reactive power controller and can thus participate in the mentioned ancillary service, is investigated later in the study. For a first instance it is assumed, that $30 \%$ are equipped with such a controller, hence this assumption guarantees a worst-case scenario regarding future development.

The operating point of HVDC converters can be chosen independently for active and reactive power due to dqdecoupling. If only the converter current is considered as limiting factor, the operational diagram shown in Figure 4 is obtained according to [12].

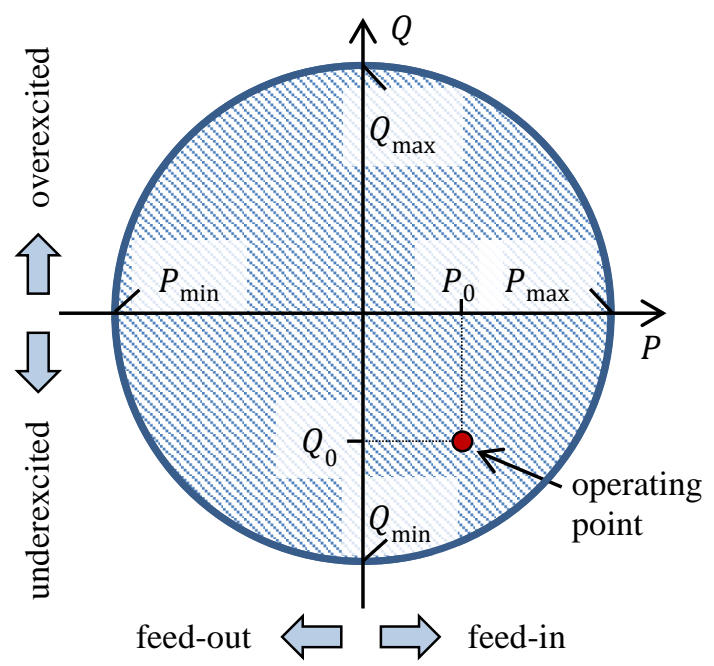

allowed area for operating point

Figure 4: Operational diagram of HVDC converter

Based on these characteristics the choice of the operating point is both important for active and reactive power transmission from an AC point of view. If the HVDC P2P link transmits maximum power, i.e. $P_{0}=P_{\max }$, voltage problems might occur due to no available reactive power reserves at the converter. Thus, the choice of the operating point is important for a reliable and stable operation and needs to be investigated. 


\section{Results}

Based on the aforementioned models and the presented methodology, different scenarios have been analyzed (subchapter A) regarding voltage stability limit (VSL) and system losses (SL). Furthermore, the influence of different converter sizes, i.e. variations in converter rated power (CRP, subchapter B), as well as reactive power supply from RES (QRES, subchapter C) have been investigated.

\section{A. Scenario Analysis}

Two different scenarios have been taken into account for the first investigations. Scenario 1 describes a situation with high feed-in from wind- and photovoltaic-sources under heavy load while scenario 2 covers a situation with low RES feed-in but also heavy load. The scenario data is shown in Table 2

\begin{tabular}{|l|l|l|} 
Table 2: Power balances for scenario 1 and 2 \\
\hline & Scenario 1 & Scenario 2 \\
\hline $\begin{array}{l}\text { Renewable Energy Sources } \\
P_{\text {RES }}\end{array}$ & $158,44 \mathrm{GW}$ & $26,55 \mathrm{GW}$ \\
\hline $\begin{array}{l}\text { Conventional Power Plants } \\
P_{\text {Conv }}\end{array}$ & $0 \mathrm{GW}$ & $50 \mathrm{GW}$ \\
\hline Consumer Loads $P_{\text {Load }}$ & $79,83 \mathrm{GW}$ & $79,83 \mathrm{GW}$ \\
\hline $\begin{array}{l}\text { Conventional Power Plants } \\
\text { Abroad } P_{\text {Conv,Abr }}\end{array}$ & $0 \mathrm{GW}$ & $3,58 \mathrm{GW}$ \\
\hline $\begin{array}{l}\text { Consumer Loads Abroad } \\
P_{\text {Load,Abr }}\end{array}$ & $72,68 \mathrm{GW}$ & $0 \mathrm{GW}$ \\
\hline
\end{tabular}

The voltage stability limit as well as the corresponding system losses are shown in Figure 5 for scenario 1 and in Figure 6 for scenario 2. Within all investigations, power transmission in both possible directions - from northern to southern converters as well as vice versa - has been analyzed.

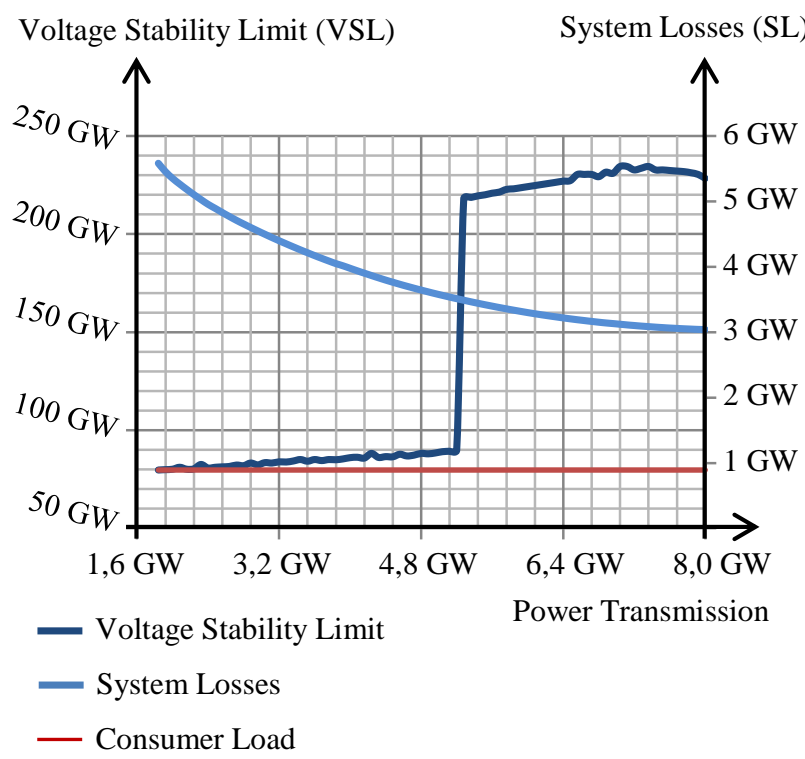

Figure 5: Voltage stability limit and system losses for scenario 1

If power is transmitted from southern to northern direction in scenario 1 , load flow does not converge at any power transmission through the HVDC-links, due to the enormous exports at southern busbars and resulting circle flows with high reactive $\mathrm{AC}$ losses. These exports are caused by a negative residual load due to high RES power feed-in.
Furthermore, load flow diverges below a converter loading of $1,84 \mathrm{GW}$ or $23 \%$ related to converter rated power of $8 \mathrm{GW}$ at the sending end, for a HVDC transmission from North to South. Due to the corresponding high stress in the AC system at these converter loadings, reactive power balance cannot be kept and thus no stable operating point can be determined. Between $23 \%(1,84 \mathrm{GW})$ and $65 \%$ $(5,2 \mathrm{GW})$ voltage stability limit is between $80 \mathrm{GW}$ and $89,85 \mathrm{GW}$, i.e. potentially at risk, due to its close distance to the operating point. The continuous rise of the stability limit at this region is caused by the increasing reduction of reactive power losses in the AC system. Starting from a converter loading of $66 \%$ or $5,28 \mathrm{GW}$ voltage stability limit steps up to values above $218 \mathrm{GW}$. The enormous step can be explained by the merit-order approach for the conventional power plants. Above a converter loading of $65 \%$, increase in load demand is high enough for one further step in merit-order, which means a high number of gas-fired power plants is connected to the grid. These power plants offer new flexibility concerning reactive power supply and thus voltage stability limit increases. Furthermore, it can be noticed that voltage stability limit remains around $230 \mathrm{GW}$ at very high dc power transmissions, i.e. at $8 \mathrm{GW}$ or $100 \%$. At this point, sending converter feeds $100 \%$ active power into the DC system, while no reactive power supply is possible (compare to Figure 4). This result has two different reasons: At sending converter, it is due to reactive power supply of RES feed-in. At receiving converter, DC system losses lead to an adequate reactive power margin and thus reactive power flexibility. Hence reactive power balance of the surrounding AC busbars can be maintained. Following these arguments, it can be concluded, that from voltage stability point of view all converter loadings with $66 \%$ or higher are sufficient for a safe operation mode. In addition, overall system losses, i.e. AC and DC system losses, are investigated. Their behavior shows that a relief of AC system - i.e. a high loading of DC system - is economical preferable due to lower DC than AC losses. Even at high converter loadings no circle flows occur, which can be seen on decreasing overall system losses. The preferred converter loading is high in this scenario.

Figure 6 shows results for scenario 2. Scenario 2 is also investigated both for North-to-South- as well as South-toNorth-power-transmission. Compared with scenario 1, results are different due to low RES feed-in. It is remarkable, that voltage stability limit is quite close to the operating point, if converters are fully loaded, both for North-to-South- and South-to-North-power-transmission. Furthermore, overall system losses are high in these operating cases, which clearly indicates loop flows in the system. Voltage stability limit is higher than $100 \mathrm{GW}$ and thus sufficient for South-to-North-power-transmission and furthermore for all converter loadings lower than $90 \%$, if power is transmitted from North-to-South through DC system. Overall system losses show that the most beneficial operating point is at $3 \%$ power transmission, while power is transmitted from South to North. These results can be explained by the positions of the conventional power plants, which are near load centers. If less RES feed power into the system, these conventional power plants cause small power transmission distances and low losses. If long distance power transmission is 
forced by corresponding HVDC converter set points, loop flows will result, which increase overall power system losses.

Voltage Stability Limit (VSL)

System Losses (SL)

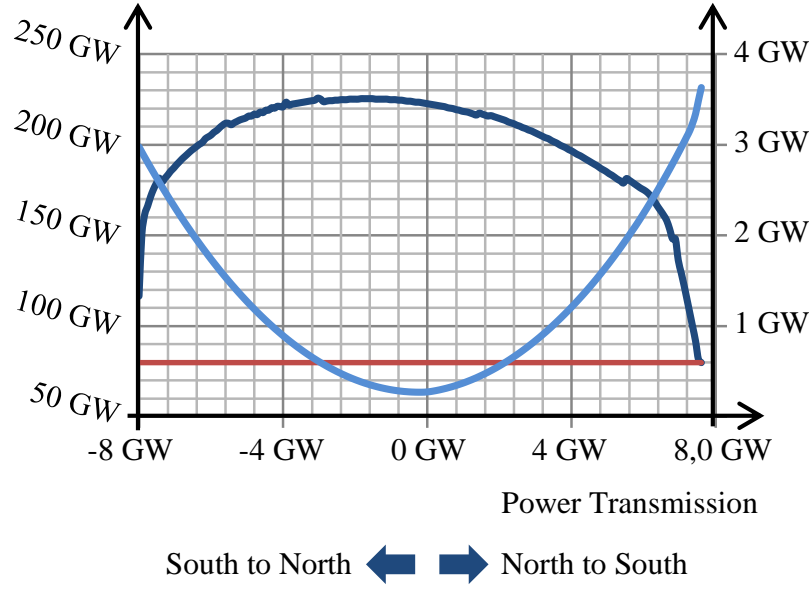

— Voltage Stability Limit

- System Losses

— Consumer Load

Figure 6: Voltage stability limit and system losses for scenario 2

Based on these results it is concluded, that power transmission through long DC systems is only beneficial, if there are sufficient differences between power supply and load among the regions of the corresponding converters. Otherwise 'STATCOM' operational mode of the HVDC converters is more beneficial.

\section{B. Influence of Converter Rated Power}

For the investigation of the influence of the converter size scenario 3 has been taken into account. Its main characteristic is a strong-wind and heavy-load situation, while the feed-in from photovoltaics is low. The corresponding power balances are provided in Table 3 . Table 3: Power balances for scenario 3

\begin{tabular}{|l|l|}
\hline & Scenario 3 \\
\hline Renewable Energy Sources $P_{\mathrm{RES}}$ & $107,77 \mathrm{GW}$ \\
\hline Conventional Power Plants $P_{\mathrm{Conv}}$ & $0 \mathrm{GW}$ \\
\hline Consumer Loads $P_{\mathrm{Load}}$ & $79,83 \mathrm{GW}$ \\
\hline Conventional Power Plants Abroad $P_{\text {Conv,Abr }}$ & $0 \mathrm{GW}$ \\
\hline Consumer Loads Abroad $P_{\text {Load,Abr }}$ & $24,16 \mathrm{GW}$ \\
\hline
\end{tabular}

The voltage stability limit as well as the corresponding system losses both for CRP $=8 \mathrm{GW}$ and $\mathrm{CRP}=4 \mathrm{GW}$ are shown in Figure 7.

Results of Scenario 3 with standard converter rating ( $8 \mathrm{GW}$ ) show slightly different behavior than scenario 1 . Power transmission from southern to northern direction has not been investigated due to the high feed-in from wind power plants, which cause a supply surplus in northern areas. In opposite to scenario 1, all converter loadings for North-toSouth-power-transmission result in a stable operating point, even if voltage stability might be at risk for converter loadings below $29 \%$ or $2,3 \mathrm{GW}$. The following step in voltage stability limit can be explained by the entry of gas- fired power plants at this point, similar to scenario 1. Gasfired power plants are applied earlier in this scenario than in scenario 1 due to lower system stress. Lower system stress is caused by shorter transmission distances due to lower RES feed-in and lower power exports. Voltage stability limit is sufficient for all converter loadings between $29 \%$ and $99 \%$. It is further notable, that a power transmission of $8 \mathrm{GW}$, i.e. a loading of $100 \%$, leads to decrease of voltage stability limit to $84,95 \mathrm{GW}$. Hence voltage stability is at risk at this converter loading, because the close distance from voltage stability limit to the operating point might cause a voltage collapse if consumer loads increase. This difference to scenario 1 can be explained by shorter transmission distances again, caused by lower RES feeds-in, lower exports and lower system stress again, which is also visible in overall system losses. Overall system losses decrease for converter loadings below $84 \%$ or $6,72 \mathrm{GW}$, while they slightly increase for higher converter loadings. This means, that system stress is slightly increased due to loop flows for higher converter loadings, which leads voltage stability to drop at fully loaded converter.

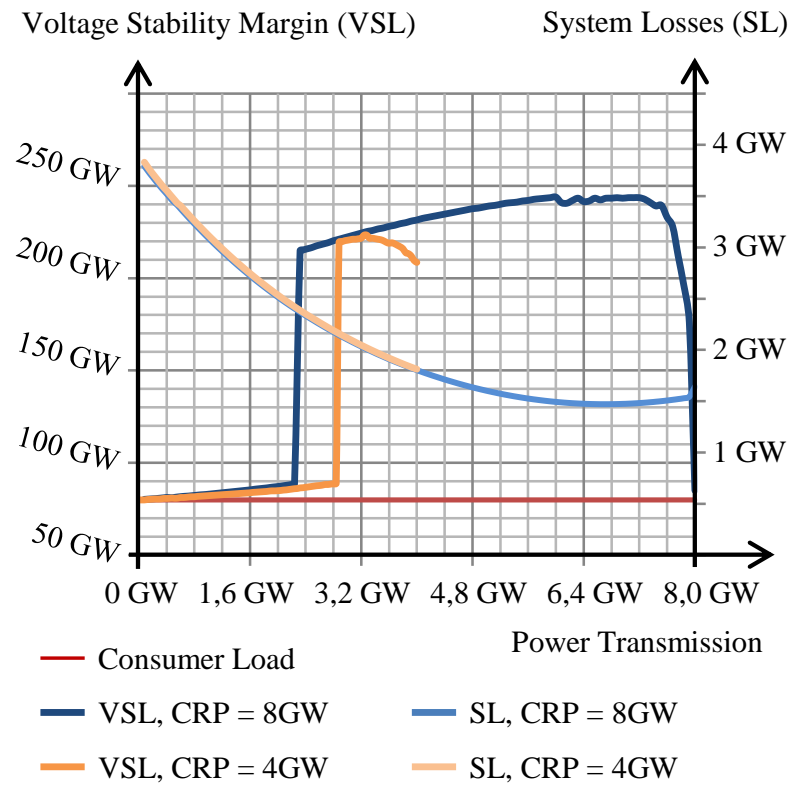

Figure 7: Voltage stability limit and system losses for scenario and variation of converter rated power

Besides the differences between scenario 1 and 3, focus may also be on the influence of converter rated power. The comparison between $\mathrm{CRP}=8 \mathrm{GW}$ and $\mathrm{CRP}=4 \mathrm{GW}$ shows only slight differences. It is notable that the step-up caused by the gas-fired power plants is applied later to the system, due to this reason. I.e. with $\mathrm{CRP}=4 \mathrm{GW}$ voltage stability is at risk below $2,88 \mathrm{GW}$ of converter loading, while it is at risk below a loading of $2,3 \mathrm{GW}$ for CRP = $8 \mathrm{GW}$. This is due to the reduced flexibility to provide reactive power in the second case with lower converter rated power. Furthermore, it is noteable that the converter rating does not have any influence on overall system losses, due to the fact that active power load flow is not affected by this issue. 


\section{Influence of RES Reactive Power Supply}

To investigate the influence of the reactive power supply from RES, three different variations have been taken into account. The first one assumes that no RES supplies reactive power. Second and third variation assume that $30 \%$ or respectively $60 \%$ of all RES supply reactive power to the system. Voltage stability limits as well as corresponding system losses are shown in Figure 8.

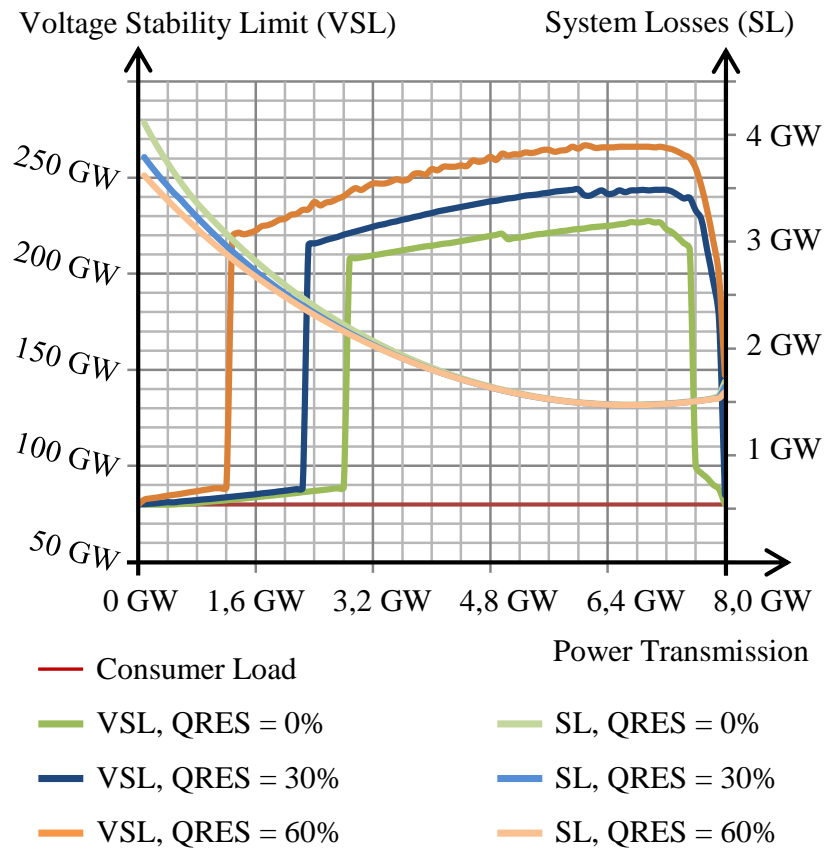

Figure 8: Voltage stability limit and system losses for scenario 3 and variation of q-controlled RES

Results show a severe influence of the amount of RES, which can supply reactive power, on voltage stability limit. If no RES can supply reactive power (QRES $0 \%$ ), voltage stability limit is the lowest for all converter loadings, because reactive power flexibility is low. With a higher amount of RES, which can supply reactive power, this flexibility rises and thus, voltage stability limit increases. For the three investigated variations, voltage stability limit is highest, if $60 \%$ of RES can supply reactive power (QRES $60 \%$ ), followed by an amount of $30 \%$ (QRES $30 \%$ ). Due to this characteristic it is expected, that voltage stability limit will increase, if even more RES will supply reactive power. It is notable, that for all three variations one range of converter loadings can be identified, where voltage stability is not at risk. The smallest range appears for QRES $0 \%$ (36\% until $94 \%$ or $2,88 \mathrm{GW}$ until $7,52 \mathrm{GW}$ ), followed by QRES $30 \%$ (29\% until $99 \%$ or $2,32 \mathrm{GW}$ until $7,92 \mathrm{GW}$ ) and QRES $60 \%$ (16\% until $100 \%$ or $1,28 \mathrm{GW}$ until $8 \mathrm{GW})$. The higher range with higher QRES can explained by the aforementioned higher reactive power flexibility, supplied to the system. It is concluded from these investigations, that reactive power supply from RES has a positive influence on voltage stability, even if the considered power system is able to cope with voltage stability also without reactive power supply from RES.

\section{Conclusions}

The investigations have shown the positive influence of HVDC P2P links on static voltage stability. Application of HVDC systems in the transmission grid is beneficial, if there are long-distances between regions with large differences between generation and load. In this case high power transmission through HVDC P2P links can guarantee a voltage stability limit, whose distance to the operating point is sufficient. In addition, low overall system losses can be reached. Furthermore, it was shown that rated power of the converters as well as the amount of RES, which can supply reactive power, affect voltage stability and must thus be taken into account for the choice of power transmission through the HVDC links.

\section{Acknowledgement}

The authors gratefully acknowledge the contribution of the Federal Ministry of Economic Affairs and Energy Germany.
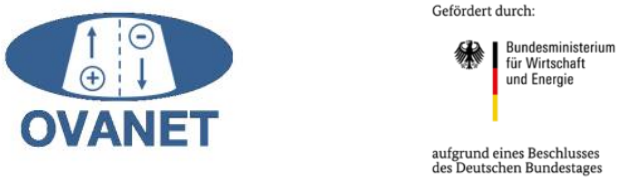

\section{References}

[1] S. Dierkes, F. Bennewitz, M. Maercks, L. Verheggen and A. Moser, "Impact of Distributed Reactive Power Control of Renewable Energy Sources in Smart Grids on Voltage Stability of the Power System", IEEE, 2014.

[2] TU Berlin, TU Ilmenau, TU Darmstadt et. al., OVANETProjektwebsite, [Online]. Available: http://www.ovanet.de. [Accessed 31 Oct. 2015].

[3] Deutsche Energie-Agentur (dena), "dena-Netzstudie II Integration erneuerbarer Energien in die deutsche Stromversorgung im Zeitraum 2015-2020 mit Ausblick auf 2025", Berlin, 2010.

[4] S. Kämpfer and G. Kopatsch, "ABB Schaltanlagen Handbuch", Mannheim, 2015.

[5] Bundesverband der Energie- und Wasserwirtschaft (BDEW), "BDEW-Kraftwerksliste 2015", Berlin, 2015.

[6] P. Kundur, "Definition and classification of power system stability", IEEE Transactions on Power Systems, 2004.

[7] P. Kundur, "Power System Stability and Control", New York, MacGraw-Hill lnc., 1994.

[8] R. D. Zimmermann, C. E. Murillo-Sanchez and R. J. Thomas, "Matpower: Steady-State Operations, Planning and Analysis Tools for Power Systems Research and Education", IEEE, 2011.

[9] M. Koepp, S. Mellahn and F. Peter, "Bedarf an konventioneller Kraftwerkskapazität in Deutschland", Berlin, 2011.

[10] C. Kost and J. Mayer, "Stromgestehungskosten Erneuerbare Energien", Freiburg, 2013.

[11] BDEW, "Technische Richtlinie Erzeugungsanlagen am Mittelspannungsnetz", Berlin, 2008.

[12] J. Hanson and P. Sandeberg, "Selbstgeführte Umrichter im elektrischen Versorgungsnetz", ETG, 2005. 